\title{
Tuberculosis Infection Could Mimic Malignant Lymphoma In F-18 FDG PET: A Case Report
}

\author{
Ryan Yudistiro* 1,2, Ivana Dewi Mulyanto 2, Febby Hutomo 2, Daniel Chung 2, Andree \\ Kurniawan ${ }^{3}$, Fajar L. Gultom ${ }^{4}$, Ralph Girson Gunarsa ${ }^{5}$ \\ ${ }^{1}$ Department of Nuclear Medicine, School of Medicine of Pelita Harapan University, Mochtar Riady Comprehensive \\ Cancer Centre Siloam Hospital, Jakarta, Indonesia \\ ${ }^{2}$ Department of Nuclear Medicine, Mochtar Riady Comprehensive Cancer Centre Siloam Hospital, Jakarta, Indonesia \\ ${ }^{3}$ Department of Internal Medicine, Faculty of Medicine, Pelita Harapan University, Karawaci, Tangerang, Banten, Indonesia \\ ${ }^{4}$ Department of Anatomical Pathology, Mochtar Riady Comprehensive Cancer Centre Siloam Hospital, Jakarta, Indonesia \\ ${ }^{5}$ Department of Hematology and Oncology, Mochtar Riady Comprehensive Cancer Centre Siloam Hospital, Jakarta, Indonesia
}

\section{ARTICLE INFO}

Received : 28 January 2020

Reviewed : 28 January 2020

Accepted : 05 August 2020

Keywords:

FDG, lymphoma, PET, tuberculosis

*Corresponding author:

Ryan Yudistiro

Department of Nuclear Medicine,

Mochtar Riady Comprehensive Cancer

Centre Siloam Hospital, Jakarta,

Indonesia

ryan.yudistiro@siloamhospitals.com

\section{A BSTRACT}

\begin{abstract}
Introduction: Lymphoma and tuberculosis in several cases share similar clinical features that are difficult to differentiate. Lymphadenopathy, fever, malaise, weight loss, and respiratory symptoms are clinical features that could be found in both lymphoma and tuberculosis. Positron Emission Tomography/Computed Tomography Fluorodeoxyglucose (F-18 FDG PET) is a pivotal modality for imaging patients with cancer. Several non-malignant diseases like tuberculosis infection show high FDG uptake and lead to low specificity of F-18 FDG PET.
\end{abstract}

Case Presentation: This case report describes a 55-year-old male patient with a history of Diffuse Large B-cell Lymphoma (DLBCL) who was suspected of having a recurrent disease. The patient has had a 6-month remission period after 6 cycles of R-CHOP regimen chemotherapy. He denied any known history of tuberculosis infection and HIV. F-18 FDG PET was performed to assess the extent of suspected lymphoma recurrent disease. F-18 FDG PET demonstrated multiple hypermetabolic bilateral neck region, mediastinum, and bilateral axilla lymphadenopathies. There were also multiple high FDG uptakes in the liver, mesocolon, and bones. The patient was suspected of having a lymphoma recurrent disease based on these findings. He underwent an excisional biopsy in the neck and was found to have lymphadenitis granulomatous disease from tuberculosis. Based on the histopathology finding, the patient received anti-tuberculosis drugs for 12 months and showed relief of signs and symptoms. F-18 FDG PET for anti-tuberculosis treatment evaluation revealed a complete metabolic response.

Conclusion: Tuberculosis should be one of the differential diagnoses when a lymphoma recurrent disease is suspected. Clinical features, laboratory results, and imaging findings sometimes show similarities between lymphoma and tuberculosis. Histopathology evaluation is mandatory to confirm the diagnosis.

\section{INTRODUCTION}

Lymphoma is a malignant transformation of the lymph nodes and lymphoid tissue. Tuberculosis is an infection caused by Mycobacterium tuberculosis [1]. Lymphoma is the sixth most common cancer in Indonesia [2]. Tuberculosis infection is endemic in developing countries with a high mortality rate. In Indonesia, the prevalence of tuberculosis is 759 out of 100,000 population with the age of $>15$ years [3]. We report a case of clinical suspicion of having lymphoma recurrent disease with false-positive Positron Emission Tomography/
Computed Tomography Fluorodeoxyglucose (F-18 FDG PET) and final tuberculosis infection confirmed by histopathology finding.

Lymphoma and tuberculosis might present similar clinical features although both are different disease entities. Lymphoma has a relatively worse prognosis compared to tuberculosis; hence, early disease differentiation is important to commence precise treatment [1].

Lymphadenopathy, fever, weight loss, malaise, and respiratory symptoms are clinical features that could be shared in lymphoma and tuberculosis $[1,4,5]$. 
Tuberculosis is diagnosed with histopathology examination or bacterial culture. Imaging procedures are routinely performed for post-treatment evaluation in lymphoma and tuberculosis. F-18 FDG PET is a pivotal modality for imaging patients with cancer. However, F-18 FDG PET has low specificity in several non-malignant diseases like tuberculosis as the infection might show high FDG uptake $[6,7]$.

\section{CASE PRESENTATION}

A 55-year-old male patient was admitted to our center with multiple lymphadenopathies and a spleen mass found from the contrast-enhanced abdominal computed tomography (CT) scan. The patient denied any history of either tuberculosis infection or HIV. Surgery was performed to excise the spleen mass, and the diagnosis of diffuse large B-cell lymphoma (DLBCL) was made from the histopathology finding. Baseline pre-chemotherapy F-18 FDG PET demonstrated stage IV lymphoma involving lymph nodes (above and under diaphragm) and bone marrow. The patient received 6 cycles of high-dose R-CHOP chemotherapy regimens and showed remission for 6 months afterward. He subsequently complained of having a new mass in the neck, weight loss of ten kilograms in two months, and fever (more than $38^{\circ} \mathrm{C}$ ). Another F-18 FDG PET was performed for restaging suspected recurrent lymphoma and found multiple new hypermetabolic lymphadenopathies in the neck, mediastinum, and bilateral axilla (not seen in the initial F-18 FDG PET). F-18 FDG PET also found hypermetabolic lesions in the liver, mesocolon, and bones (Figure 1). The patient underwent an excisional biopsy in the neck mass which was confirmed to be lymphadenitis granulomatous disease from tuberculosis (Figure 2). He received antituberculosis drugs for 1 year and showed good response, clinical health improvement, and neck mass regression. This response was confirmed by post-anti-tuberculosis therapy F-18 FDG PET showing a complete metabolic response (Figure $\mathbf{3}$ ).

F-18 FDG PET acquisition was performed using a PET camera (Gemini, Phillips Healthcare, US). A Dose of $0.10 \mathrm{mCi} / \mathrm{kgBW}$ FDG was intravenously administered to the patient after 6-hour fasting with a blood glucose level of less than $150 \mathrm{mg} / \mathrm{dl}$. FDG was administered 45-90 minutes before the acquisition. Low-dose CT was applied with a slice thickness of $10 \mathrm{~mm}$. The three-dimensional acquisition was done for $180 \mathrm{sec}$ per bed position followed by a reconstruction model with the $3 \mathrm{D}$-ordered-subsets expectation maximization method.

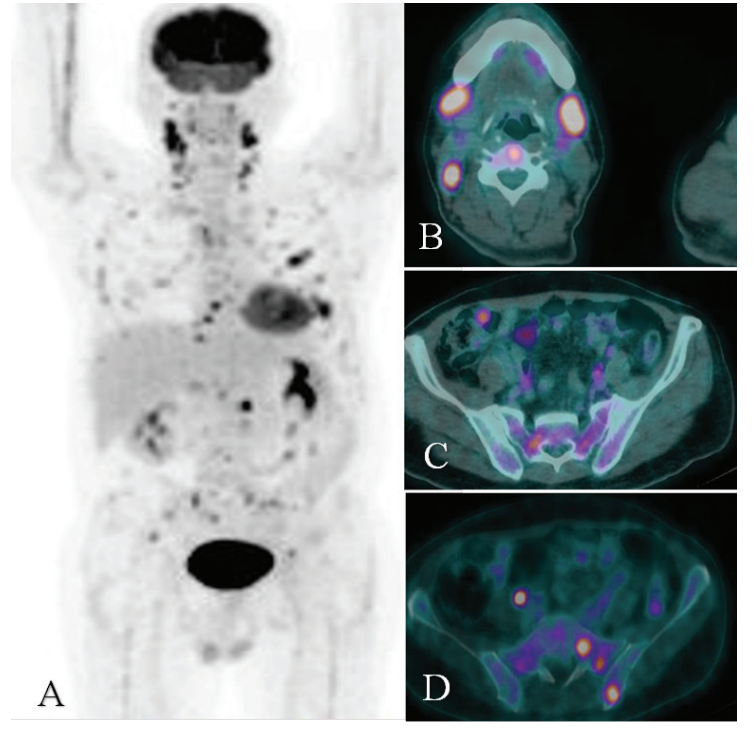

Figure 1. (A, B, C, D) F-18 FDG PET suggestive for lymphoma recurrent (before anti-tuberculosis treatment)

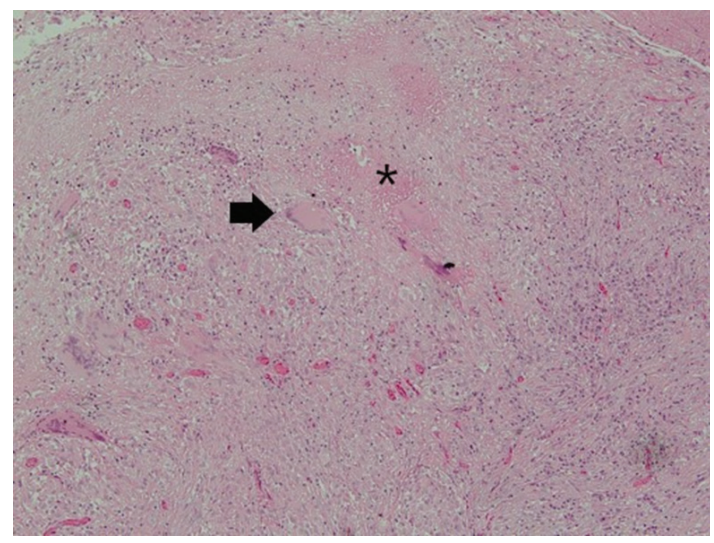

Figure 2. Histopathological examination of neck lymphadenopathy showed caseous necrotic area $\left({ }^{*}\right)$ and Langhans datia cells (black arrow)

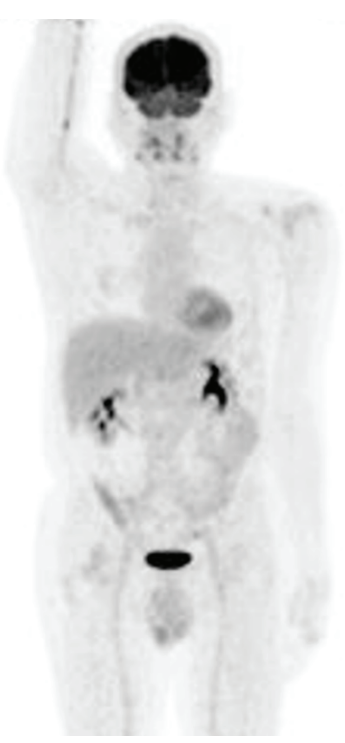

Figure 3. F-18 FDG PET after anti-tuberculosis treatment suggestive for complete metabolic response 


\section{DISCUSSION}

Our case report depicts a tuberculosis patient with a history of lymphoma showing clinical features and F-18 FDG PET findings of lymphoma recurrent disease. Misdiagnosis could increase morbidity and mortality rates. Accurate tuberculosis diagnosis can be obtained by histopathology examination or bacterial culture.

Tuberculosis is a "great imitator" that can mimic other several diseases including malignant lymphoma. Tuberculosis usually affects the lungs; however, it can also involve extrapulmonary organs such as the lymph node. The lymph node is one of the extrapulmonary organs that are most commonly infected by tuberculosis. It is difficult for clinicians to non-invasively differentiate lymphadenopathy due to lymphoma or tuberculosis [1].

Tuberculosis rapidly grows and develops in patients with an impaired immune system or an immunecompromised state. This might be due to the immune suppression related to lymphoma malignancy or postchemotherapy adverse effects in addition to living in an endemic region of tuberculosis. Tuberculosis is usually found in immunocompromised individuals, such as HIV and cancer patients. The immune suppression, in this case, might be related to lymphoma malignancy and post-chemotherapy adverse effects. Chemotherapy is the treatment of choice for lymphoma with the adverse effect of immune suppression. The compromised immune system enables Mycobacterium tuberculosis to easily infect patients, especially those living in the endemic region $[8,9]$.

Diagnostic imaging has important roles in diagnoses and treatment evaluation for both tuberculosis and lymphoma cases (Table 1 ). Chest X-Ray is routinely performed for patients having suspected lung tuberculosis. Meanwhile, CT, magnetic resonance imaging (MRI), or PET could evaluate both pulmonary and extrapulmonary tuberculosis. CT is preferred for evaluating tuberculosis in the chest, gastrointestinal, and urogenital systems. MRI is preferred for evaluating tuberculosis in the central nervous system [10]. F-18 FDG PET has been widely used for staging and treatment response evaluation in lymphoma. F-18 FDG PET detects relapse disease earlier than anatomical imaging such as CT or MRI [11]. F-18 FDG PET could differentiate indolent and aggressive lymphoma. F-18 FDG PET demonstrates lower FDG uptake in indolent than in aggressive lymphoma [12].

One of F-18 FDG PET limitations is low specificity. FDG is accumulated not only in tumor cells but also in macrophage cells, granulation tissue, or inflammation tissue. FDG avidity represents the glucose metabolism level of the tumor cell and inflammation process. FDG is a glucose analog that is transported inside cells via glucose-transporter (GLUT) protein. Lymphadenopathy in tuberculosis and lymphoma shows high FDG uptake. The maximum standard uptake value (SUV max) could not accurately differentiate between tuberculosis and lymphoma lymphadenopathy.

Table 1. Comparison between F-18 FDG PET and MRI for the detection of lymphoma [11].

\begin{tabular}{|c|c|c|}
\hline Modality & Advantages & Disadvantages \\
\hline $\begin{array}{l}\text { F-18 } \\
\text { FDG } \\
\text { PET }\end{array}$ & $\begin{array}{l}\text { Higher sensitivity for } \\
\text { le sion detection } \\
\text { helps detect splenic } \\
\text { T-cell lymphoma }\end{array}$ & $\begin{array}{l}\text { Low specificity; } \\
\text { inflammation is also } \\
\text { detected; gastric MALT } \\
\text { lymphoma and cerebral } \\
\text { lymphoma are not } \\
\text { detected* }\end{array}$ \\
\hline MRI & $\begin{array}{l}\text { Higher sensitivity for } \\
\text { lesion detection can } \\
\text { help detect more } \\
\text { subcutaneous lesion }\end{array}$ & $\begin{array}{l}\text { Normal lymph nodes } \\
\text { are also detected, } \\
\text { mediastinum lesions } \\
\text { are not detected** }\end{array}$ \\
\hline CT scan & $\begin{array}{l}\text { First-line diagnostic } \\
\text { imaging of systemic } \\
\text { disease }\end{array}$ & $\begin{array}{l}\text { Less accurate for the } \\
\text { initial staging and } \\
\text { evaluation of treatment } \\
\text { response }\end{array}$ \\
\hline
\end{tabular}

Note. MALT: Mucosa Associated Lymphoid Tissue

*Owing to physiologic gastric and brain cortical accumulation of FDG

**Owing to the artifact caused by cardiovascular motion

Some studies have reported several methods in differentiating infection and malignancy based on F-18 FDG PET acquisition protocols, characteristics, and parameters. At first, a threshold of SUV max value is proposed to distinguish between infection and malignancy. Another method is using dual-time F-18 FDG PET imaging acquisition protocol, based on varying levels of glucose-6-phosphatase activities among different tumor cell types, inflammatory, and normal cells. The most recent method is using the influx rate constant (Ki) which is reported to be closely related to neutrophil activation. However, these methods are not well validated as several other factors could also influence FDG uptake and are not applicable in daily clinical practice [13]. Good knowledge of specific malignant disease patterns and correlation with other modalities such as tumor marker and anatomical imaging is important for F-18 FDG PET interpretation in the clinical setting. It is also important to always consider some tumor markers and other clinical assessment pitfalls commonly used in diagnosing malignancy. New specific radiopharmaceutical for tuberculosis such as Tc-99m Ethambutol might also be helpful in this setting [14]. 


\section{CONCLUSIONS}

Tuberculosis and lymphoma are two different disease entities with similar clinical features and diagnostic imaging findings. It makes a differentiation between the two entities difficult. Tuberculosis is a "Great Imitator" for several other diseases including malignant lymphoma. Tuberculosis infection should be considered as a differential diagnosis when interpreting F-18 FDG PET in a patient with a history of lymphoma who had received chemotherapy and live in a developing country.

\section{DECLARATIONS}

\section{Competing of Interest}

No potential conflict of interest relevant to this article was reported.

\section{Acknowledgment}

Not Applicable

\section{REFERENCES}

1. Uy AB, Garcia AM, Manguba A, Loyola A. Tuberculosis: the great lymphoma pretender. Int J Cancer Res Mol Mech. 2016;2(1):2-5.

2. Pusat Data dan Informasi Kementerian Kesehatan Republik Indonesia. Infodatin-limfoma 2015. Vol. 1, Infodatin. 2015. p. 1-6.

3. Marlina I. Tuberkulosis. Infodatin (Pusat Data dan Informasi Kesehatan RI) [Internet]. 2018;2(1):3-4. Available from: https://pusdatin.kemkes.go.id/ resources/download/pusdatin/infodatin/infodatintuberkulosis-2018.pdf

4. Thakkar K, Ghaisas SM, Singh M. Lymphadenopathy: Differentiation between tuberculosis and other nontuberculosis causes like follicular lymphoma. Front Public Heal. 2016;4:10-3.
5. Dres M, Demoule A, Schmidt M, Similowski T. Tuberculosis hiding a non-Hodgkin lymphoma "there may be more to this than meets the eye." Respir Med Case Reports. 2012;7(1):15-6.

6. Soussan M, Brillet PY, Mekinian A, et al. Patterns of pulmonary tuberculosis on FDG-PET. Eur J Radiol. 2012;81(10):2872-6.

7. Jehanno $N$, Cassou-Mounat $T$, Vincent-Salomon $A$, et al. PET imaging in management of concomitant Hodgkin lymphoma and tuberculosis - a problem solver tool. Clin Case Reports. 2018;6(1):232-4.

8. Falagas ME, Kouranos VD, Athanassa Z, Kopterides $P$. Tuberculosis and malignancy. QJM. 2010;103(7):461-87.

9. Dobler CC, Cheung K, Nguyen J, Martin A. Risk of tuberculosis in patients with solid cancers and haematological malignancies: A systematic review and meta-analysis. Eur Respir J. 2017;50(2):1700157.

10. Bomanji JB, Gupta N, Gulati P, Das CJ. Imaging in tuberculosis. Cold Spring Harb Perspect Med. 2015;5(6):1-23.

11. Okada M, Sato N, Ishii K, et al. F-18 F-18 FDG PET versus $\mathrm{CT}, \mathrm{MR}$ imaging, and $67 \mathrm{Ga}$ scintigraphy in the post therapy evaluation of malignant lymphoma. Radiographics. 2010;30:939-57.

12. Schoder H. Intensity of 18 Fluorodeoxyglucose uptake in positron emission tomography distinguishes between indolent and aggressive Non-Hodgkin's Iymphoma. J Clin Oncol. 2005;23(21):4643-51.

13. Zuang $H$, Pourdehnad $M$, Lambright ES, et al. Dual time point 18F-F-18 FDG PET imaging for differentiating malignant from inflammatory process. J Nucl Med. 2001;42:1412-7.

14. Kartamihardja AHS, Kurniawati Y, Gunawan R. Diagnostic value of $99 \mathrm{mTc}$-ethambutol scintigraphy in tuberculosis: Compared to microbiological and histopathological tests. Ann Nucl Med. 2018;32(1):60-8. 